\title{
La Bretagne Linguistique, un anniversaire
}

\section{(2) OpenEdition}

1 Journals

Édition électronique

URL : http://journals.openedition.org//bl/418

DOI : $10.4000 / \mathrm{lbl} .418$

ISSN : 2727-9383

Éditeur

Université de Bretagne Occidentale - UBO

\section{Édition imprimée}

Date de publication : 1 mars 2016

Pagination : 7-8

ISBN : 979-10-92331-24-0

ISSN : $1270-2412$

\section{Référence électronique}

"La Bretagne Linguistique, un anniversaire », La Bretagne Linguistique [En ligne], 20 | 2016, mis en ligne le 01 mai 2020, consulté le 01 octobre 2020. URL : http://journals.openedition.org//bl/418 ; DOI : https://doi.org/10.4000/lbl.418

\section{(c) (i)}

La Bretagne Linguistique est mise à disposition selon les termes de la Licence Creative Commons Attribution 4.0 International. 


\section{La Bretagne Linguistique, un anniversaire}

Le premier volume de La Bretagne Linguistique est paru en 1985. Fondé par Yves Le Berre et Jean Le Dû l'année précédente, le GRELB (Groupe de recherche sur l'économie linguistique de la Bretagne) avait " pour ambition de devenir le champ ouvert où s'échanger[aie]nt et se discuter[aie]nt les idées et les savoirs nouveaux sur notre région ${ }^{1} »$. En trente ans, le groupe a ainsi organisé près de soixante journées de séminaire qui ont rassemblé 188 intervenants devant un public varié composé d'enseignants, de chercheurs et d'étudiants. Même si des évolutions sont perceptibles dans le temps, globalement, les sujets de prédilection des membres du GRELB sont restés les mêmes que ceux mentionnés dans le premier numéro ${ }^{2}$, à savoir :

- la sociolinguistique : c'est dans le cadre de ce séminaire qu'on été menées des recherches d'importance sur la sociolinguistique du breton $^{3}$;

- la dialectologie et la géographie linguistique : le numéro 13 de la revue est entièrement consacré à ces disciplines

- la phonologie, la morphologie, la syntaxe ;

- la linguistique ;

- les littératures écrite et orale et la sociolittérature.

Ce numéro regroupe, comme à l'accoutumée, les articles issus des communications présentées lors de trois journées de séminaire annuel des 14 février, 6 juin et 5 décembre 2014 et marque également le trentième anniversaire du groupe. Il nous a donc semblé être le moment d'établir un bilan chiffré reprenant les données des vingt premiers numéros de la revue.

1. Jean Le Dû et Yves Le Berre, La Bretagne Linguistique, nº 1, Brest, CRBC, 1985.

2. Cf. ibidem, $4 \mathrm{e}$ de couverture.

3. C'est dans le cadre du GRELB, notamment, qu'ont été organisés les deux colloques suivants en 1995 et 1997 : «Badume - Standard - Norme / Le double jeu de la langue » (cf. La Bretagne linguistique, $\mathrm{n}^{\circ} 10$, Brest, CRBC, 1996) et « Y a-t-il une exception socio-linguistique française? » (cf. La Bretagne Linguistique, $\mathrm{n}^{\circ} 12, \mathrm{CRBC}, 1998$ ). 
Enfin, nous avons également choisi de proposer en fin de numéro trois index reprenant les articles déjà parus et classés :

- par numéro de revue ;

- par ordre alphabétique d'auteur ;

- par discipline scientifique. 